\title{
Heterogeneous Decomposition of Trichlorofluoromethane on Carbonaceous Surfaces
}

\author{
Agustin J. Colussi* and Valentin T. Amorebieta \\ Department of Chemistry, University of Mar del Plata, 7600 Mar del Plata, Argentina
}

\begin{abstract}
The interaction of trichlorofluoromethane with activated charcoal has been investigated by dynamic mass spectrometry up to $750 \mathrm{~K}$. Prior physical adsorption, revealed in programmed desorption experiments, is followed by irreversible first-order decay with formation of nearly equimolar amounts of $\mathrm{HCl}$ above $550 \mathrm{~K}$. This unexpectedly fast process has an apparent activation energy of only $59.4 \mathrm{~kJ} \mathrm{~mol}^{-1}$ and is demonstrably catalytic. The mechanism of $\mathrm{Cl}_{3} \mathrm{CF}$ decomposition on carbon surfaces and its possible impact on atmospheric chemistry are discussed.
\end{abstract}

We have recently presented direct evidence showing that carbon surfaces efficiently catalyse the atomization of molecular chlorine and the breakdown of polychlorinated methanes. ${ }^{1}$ Such results are particularly relevant to the free-radical mechanisms underlying the synthesis and decomposition of chlorocarbons and, moreover, provide a rationalisation for the erratic kinetic behaviour often observed in such systems. ${ }^{2}$ Early reports had already identified charcoal as a catalyst in thermal chlorinations. ${ }^{3}$

Since carbon is the most abundant element associated with pollution particulates, ${ }^{4}$ and considering that the collision frequency between gas molecules and particles in highly contaminated urban environments can reach up to $c a .1 \mathrm{~s}^{-1},{ }^{5}$ and that current estimates of the tropospheric lifetime of chlorofluorocarbons span the wide range 30 150 years, we decided to undertake studies on the decay of $\mathrm{Cl}_{3} \mathrm{CF}$ with the specific goal of assessing the likelihood of its decomposition on atmospheric carbonaceous surfaces. ${ }^{6-8}$ Clearly we face one of those rare kinetic problems which require one to explore chemical change over long, rather than short, time periods. ${ }^{9}$ The results reported in this paper confirm the remarkable activity of carbonaceous surfaces towards chlorocarbon decomposition and, in conjunction with simple considerations, suggest the possibility of an active role for soot as a tropospheric sink for such species.

\section{Experimental}

Kinetic studies were performed in a $300 \mathrm{~cm}^{3}$ heated Pyrex reactor coupled to an analytical mass spectrometer (EMBA II, Extranuclear Laboratories) via a molecular leak for continuous monitoring of reactants and products. ${ }^{1}$ It was verified that $\mathrm{Cl}_{3} \mathrm{CF}$ (Freon 11 , Matheson) is perfectly stable in the gas phase below $750 \mathrm{~K}$, as expected from kinetic and thermochemical considerations. ${ }^{10}$ On the other hand the addition of small amounts $(0.5-1.0 \mathrm{~g})$ of activated carbon (Mallinckrodt, $0.5 \%$ ash, specific area $684 \mathrm{~m}^{2} \mathrm{~g}^{-1}$, as determined by nitrogen adsorption B.E.T. measurements) dispersed on glass wool to minimize mass-transfer artifacts, led to the rapid first-order decay of $\mathrm{Cl}_{3} \mathrm{CF}$ at pressures between 0.02 and 0.11 Torr in the range $555-750 \mathrm{~K}$. The most intense ion signal in the mass spectrum of the reactant at $m / z=101\left(\mathrm{Cl}_{2} \mathrm{CF}^{+}\right)$was used for this purpose. Moreover, rates were found to be proportional to the amount of carbon added, confirming the catalytic nature of a process which leads to the formation of nearly equimolar amounts of $\mathrm{HCl}$ as the sole gaseous product. The last statement was verified both by mass spectrometry and manometric measurements. However, at temperatures above 


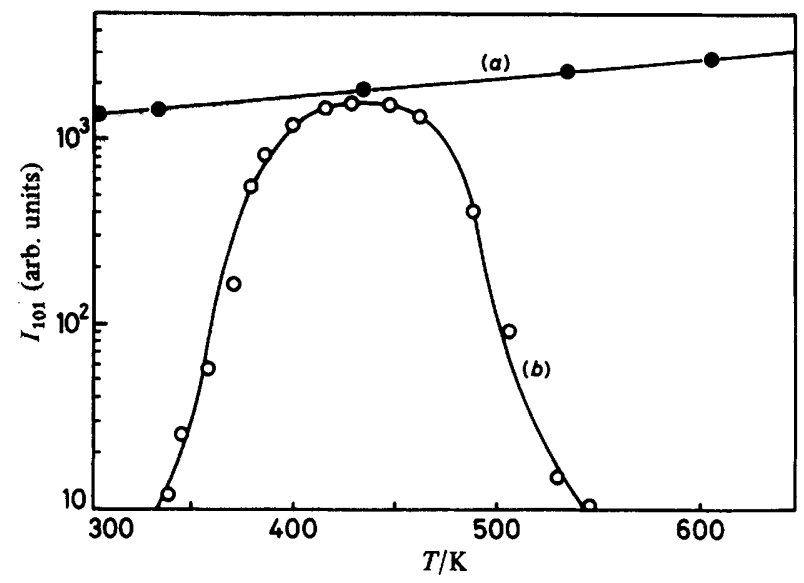

Fig. 1 (a) Intensity of the $m / z=101$ signal (in arbitrary units) in the mass spectrum of $\mathrm{Cl}_{3} \mathrm{CF}$ effusing from the empty reactor $v s$. reactor temperature (heating rate $=7.2 \mathrm{~K} \mathrm{~min}^{-1}$ ); $(b)$ the same experiment but with $0.5 \mathrm{~g}$ of carbon added. Notice that up to the onset of decomposition at $c a$. $420 \mathrm{~K}$ most of $\mathrm{Cl}_{3} \mathrm{CF}$ has desorbed.

$700 \mathrm{~K}$ additional amounts of $\mathrm{HCl}$ slowly evolved, revealing further decomposition of adsorbed products. Addition of tenfold amounts of $\mathrm{O}_{2}$ or $\mathrm{N}_{2}$ had only a minor effect on rates which were otherwise very reproducible. Gradual loss of catalyst activity was observed after several runs or by the use of large initial pressures of $\mathrm{Cl}_{3} \mathrm{CF}$ and led to the reloading of fresh batches of activated carbon. This is ascribed in part to the depletion of bound hydrogen atoms and more likely to the irreversible surface modification arising from deposition of CF fragments. Obviously this type of inactivation is not expected to be met under atmospheric conditions. Finally, physical adsorption of the gas at room temperature followed by linearly programmed desorption with a heating rate of $7.2 \mathrm{~K}$ $\mathrm{min}^{-1}$ led to its quantitative recovery prior to decomposition, indicating that chemical reaction takes place in a second-stage activated process. In this phase of our research we were primarily interested in the chemical aspects of this gas-surface interaction, so we did not attempt detailed surface characterization (fig. 1).

\section{Results and Discussion}

Rates of $\mathrm{Cl}_{3} \mathrm{CF}$ decomposition were identical to the rates of $\mathrm{HCl}$ appearance (see above):

$$
\mathrm{Cl}_{3} \mathrm{CF}(\mathrm{g})+\mathrm{C}(-\mathrm{H})(\mathrm{s}) \rightarrow \mathrm{Cl}_{2} \mathrm{FC}-\mathrm{C}(\mathrm{s})+\mathrm{HCl}(\mathrm{g})
$$

and closely followed first-order kinetics over at least three lifetimes. The corresponding rate constants, expressed in units of $\mathrm{s}^{-1} \mathrm{~g}^{-1}$ are presented in fig. 2 as function of temperature. The Arrhenius expression,

$$
\log k_{1}=4.05-59.4 / 2.303 R T
$$

fits rate data well under the present experimental conditions. The corresponding activation energy is much lower than the kinetic barrier to any conceivable gasphase unimolecular decomposition pathway for $\mathrm{Cl}_{3} \mathrm{CF}$, such as $\mathrm{Cl}_{2}$ elimination or $\mathrm{C}-\mathrm{Cl}$ bond fission, for which endothermicities of 280 and $314 \mathrm{~kJ} \mathrm{~mol}^{-1}$ can be estimated, respectively, from literature data. ${ }^{10} \mathrm{On}$ the other hand, the magnitude of the pre-exponential factor clearly points to activated adsorption as the rate limiting step. ${ }^{11}$ Thus programmed desorption experiments, the apparent first-order kinetics and observed reaction stoichi- 


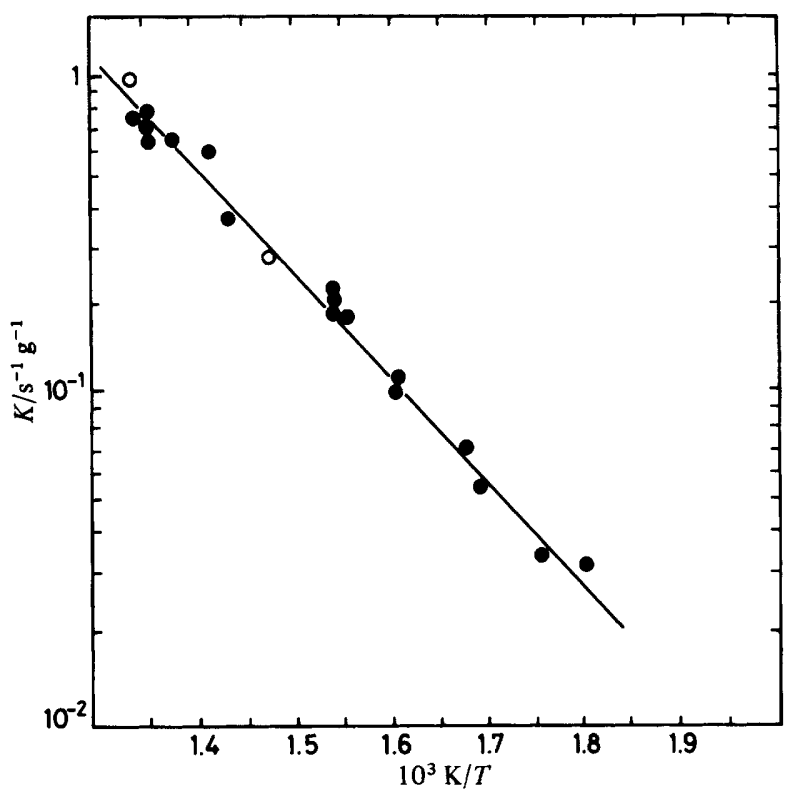

Fig. 2. First-order rate constants for the decay of $\mathrm{Cl}_{3} \mathrm{CF}$ over activated carbon per gram of catalyst as function of reciprocal temperature. Open circles correspond to rate constants for $\mathrm{HCl}$ formation.

ometry suggest that reaction (1) may actually proceed by dissociative activated chemisorption [step (c)] of species previously bound to a barely covered surface:

$$
\begin{gathered}
\mathrm{Cl}_{3} \mathrm{CF}(\mathrm{g}) \stackrel{\mathrm{a}}{\stackrel{\mathrm{b}}{\rightleftharpoons}} \mathrm{Cl}_{3} \mathrm{CF}(\mathrm{s}) \\
\mathrm{Cl}_{3} \mathrm{CF}(\mathrm{s}) \stackrel{\mathrm{c}}{\rightarrow} \mathrm{Cl}_{2} \mathrm{CF}(\mathrm{s})+\mathrm{Cl}(\mathrm{s}) \\
\mathrm{Cl}(\mathrm{s})+\mathrm{C}(-\mathrm{H}) \stackrel{\mathrm{d}}{\rightarrow} \mathrm{HCl}(\mathrm{g})+\mathrm{C}(\mathrm{s}) .
\end{gathered}
$$

Step (c) represents a purely heterogeneous discrete dissociation process. In the absence of abstractable interfacial hydrogen atoms it would be simply followed by desorption of atoms and free radicals as already found in the catalytic dissociation of $\mathrm{Cl}_{2}$ over graphitic films. ${ }^{1}$

The proposed scheme leads to an equilibrium superficial concentration of $\mathrm{Cl}_{3} \mathrm{CF}$, $\mathrm{C}_{\mathrm{F}}(\mathrm{s})$, given by eqn (II):

$$
k_{\mathrm{a}} C_{\mathrm{F}}(\mathrm{g})=C_{\mathrm{F}}(\mathrm{s}) A_{\mathrm{b}} \exp \left(-E_{\mathrm{b}} / R T\right)
$$

where $r_{\mathrm{a}}=k_{\mathrm{a}} C_{\mathrm{F}}(\mathrm{g})$ is the number of molecules striking the surface per second and unit area. Assuming that step (c) is rate-determining, the observed rate of decomposition, $r_{1}$, will be given by

$$
r_{1}=C_{\mathrm{F}}(\mathrm{g}) A_{1} \exp \left(-E_{1} / R T\right)=C_{\mathrm{F}}(\mathrm{s}) A_{\mathrm{c}} \exp \left(-E_{\mathrm{c}} / R T\right)
$$

and the probability of reaction at a single collision: $P=r_{1} / r_{\mathrm{a}}=\mathrm{k}_{1} / k_{\mathrm{a}}$, by

$$
P=\left(A_{\mathrm{c}} / A_{\mathrm{b}}\right) \exp \left(E_{\mathrm{b}}-E_{\mathrm{c}}\right) / R T .
$$

Since $k_{\mathrm{a}}=f\left(T^{\frac{1}{2}}\right)$, we finally obtain: $E_{\mathrm{c}}-E_{\mathrm{b}}=E_{1}-0.5 R T_{\mathrm{m}}=56.6 \mathrm{~kJ} \mathrm{~mol}^{-1}$. 
Further analysis shows that a lower bound of $c a .0 .1$ for the ratio of $A$-factors $\left(A_{\mathrm{c}} / A_{\mathrm{b}}\right)$ is consistent both with empirical evidence on the decomposition of gases over surfaces and also with the transition-state theory of heterogeneous processes. ${ }^{12}$ Since bond fission, step (c), essentially transforms two internal bending vibrations of the group $\mathrm{X}-\mathrm{C}-\mathrm{Cl}$ into low-frequency lattice vibrations of adsorbed chlorine atoms, transitionstate theory predicts $A_{\mathrm{c}}$ values of $c a$. of $10^{13.5}-10^{14.0} \mathrm{~s}^{-1} \cdot{ }^{13}$ Larger $A$-factors are expected for desorption, since in this case five low-frequency lattice vibrations and librations of the loosely bound adsorbate end up as translations and rotations in the gas phase. Therefore eqn (IV) reduces to: $P=0.1 \exp (-56.6 / R T)$, which would extrapolate to a value of $P=2 \times 10^{-11}$ at $300 \mathrm{~K}$. It should be emphasized that prior physisorption at ambient temperatures ensures longer residence times, and therefore under such conditions step (c) would not only compete with desorption but also with lateral diffusion into nearby active sites, thereby increasing the probability of decomposition per encounter. On the other hand the collision frequency of freon molecules with typical submicron atmospheric soot particles $\left(0.01 \mu \mathrm{m}\right.$ diameter, $\left.d=2 \mathrm{~g} \mathrm{~cm}^{-3}\right)$ at an average concentration of $1 \mathrm{mg} \mathrm{m}^{-3}$ or $n_{\mathrm{s}}=1 \times 10^{9}$ particle $\mathrm{cm}^{-3}$ can be evaluated by the standard procedures of the kinetic theory of gases and is given by $Z_{\mathrm{w}}=\pi r_{\mathrm{s}}^{2} V_{\mathrm{k}} n_{\mathrm{s}}$, or $Z_{\mathrm{w}}=15 \mathrm{~s}^{-1}$, where $r_{\mathrm{S}}$ is the radius of soot particles and $V_{\mathrm{F}}$ the average speed of freon molecules at $300 \mathrm{~K}{ }^{14}$ This estimate comes close to reported empirical values of $Z_{\mathrm{w}}=1 \mathrm{~s}^{-1.5}$ The product $Z_{\mathrm{w}} P$ then yields a pseudo-first-order rate constant for freon decomposition of ca. $3 \times 10^{-10} \mathrm{~s}^{-1}$, corresponding to a half-life of $c a$. 70 years, i.e. commensurate with the estimated residence times in the troposphere. ${ }^{6-8}$

Clearly this exercise is not actually intended to provide a precise figure for the rate of decomposition of freon on soot under atmospheric conditions, but rather to draw attention to the fact that, despite inevitable uncertainties, it yields a significant value. At this stage the atmospheric relevance of present results must be limited to the preliminary statement that carbonaceous surfaces are indeed very active for the decomposition of $\mathrm{Cl}_{3} \mathrm{CF}$ to an extent hardly predictable on the basis of its chemical inertness. Several questions remain to be explored, such as: (1) the similarity between the charcoal material used here and the undefined and necessarily variable properties of atmospheric carbon particles, and (2) the synergism or antagonism of other more abundant and reactive, albeit more lightly bound, pollutants. ${ }^{15}$ Although both aspects certainly deserve further study they can not be expected to be easily answered, since alternatives to present experiments should involve lower temperatures and the addition of $\mathrm{NO}_{x}, \mathrm{O}_{3}$ and hydrocarbons better to simulate actual atmospheric conditions. In the limit, this would amount to field-monitoring of freons.

\section{References}

1 V. T. Amorebieta and A. J. Colussi, Int. J. Chem. Kinet., 1985, 17, 849.

2 P. G. Ashmore, J. W. Gardner, A. J. Owen, B. Smith and P. R. Sutton, J. Chem. Soc, Faraday Trans. $1,1982,78,657 ; 677$.

3 J. W. Mallet, U.S. Patent, 1879, 220, 397.

4 T. Novakov, S. G. Chang and A. B. Harker, Science, 1974, 186, 259.

5 L. Brouwer, M. J. Rossi and D. M. Golden, J. Phys. Chem., 1986, 90, 4599.

6 P. S. Gumerman, L. C. Glasgow and L. C. Jesson, Atmos. Environ., 1978, 12, 1271.

7 A. J. Owens, J. M. Steed and C. Miller, Geophys. Res. Lett., 1982, 9, 700.

8 A. K. Miller, D. L. Filkin, J. P. Jesson, J. M. Steed and A. J. Owens, Nature (London), 1982, 295, 308.

9 S. W. Benson, in Reaction Kinetics (The Chemical Society, London, 1975), vol. 1, p. 4.

10 (a) D. F. McMillen and D. M. Golden, Annu. Rev. Phys. Chem., 1982, 33, 493; (b) S. G. Lias,

Z. Karpas and J. F. Liebman, J. Am. Chem. Soc., in press.

11 R. C. Baetzold and G. A. Somorjai, J. Catal., 1976, 45, 94.

12 A. J. B. Robertson, Catalysis or Gas Reactions by Metals (Logos Press, London, 1970), p. 124. 
13 S. Glasstone, K. J. Laidler and H. Eyring, The Theory of Rate Processes (McGraw-Hill, New York, 1941), chap. 7.

14 R. H. Perry and C. H. Chilton, Chemical Engineers' Handbook (McGraw-Hill, Tokyo, 5th edn, 1973), chap. 20, p. 115.

15 S. Stephens, M. J. Rossi and D. M. Golden, Int. J. Chem. Kinet., 1986, 18, 1133.

Paper 6/2493; Received 31st December, 1986 